$$
\begin{aligned}
& \text { بروسى نقش سيستم كاناينوئيدى يوستهُ هستة آكومبنس در تثبيت حافظة اجتنابى غيرفعال در رت- } \\
& \text { هاى نر نزاد ويستار }
\end{aligned}
$$

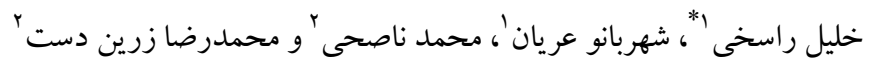

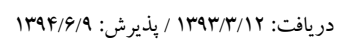

$$
\begin{aligned}
& \text { 'أرووه علوم جانورى، دانشكدة علوم زيستى، دانشگاه خوارزمى، تهران } \\
& \text { بُّزوهشكدة علوم شناختى، تهران }
\end{aligned}
$$

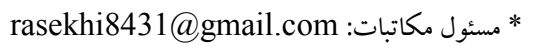

\title{
The role of cannabinoid system in consolidation of passive avoidance memory in the shell of nucleus accumbens in male Wistar rats Received 02.06.2014 / Accepted 31.08.2015
}

\author{
Khalil Rasekhi $^{{ }^{*}}$, Shahrbanoo Oryan ${ }^{1}$, Mohammad Nasehi ${ }^{2}$ and Mohammad Reza Zarrindast ${ }^{2}$
}

\author{
${ }^{1}$ Department of Animal Biology, Faculty of Biological Sciences, Kharazmi University, Tehran, Iran \\ ${ }^{2}$ Institute for Cognitive Science Studies (ICSS), Tehran, Iran \\ *Correspondent author: rasekhi8431@gmail.com
}

\begin{abstract}
There are multiple neurotransmitters and neuromodulator systems mediating memory formation among which the endocannabinoid system plays a critical role in the memory formation by modulating the release of many neurotransmitters. Nucleus accumbens appears to have a site in the central of neuronal circuits of the limbic system and to be responsible for the integration and consolidation of inputs from other parts of the brain. In this study the influence of bilateral intra-nucleus accumbens shell microinjections of cannabinoid receptor agents on memory consolidation in adult male rats using passive avoidance task was investigated. The results showed that the intra-accumbens shell microinjection of ACPA as a CB1 receptor agonist (6 ng/rat) immediately after training decreased passive avoidance memory consolidation, while administration of its antagonist (AM251) at different doses did not affect passive avoidance memory consolidation. However, co-administration of AM251 (60 ng/rat) with an effective dose of ACPA prevented the impairment memory consolidation induced by ACPA. These results suggest that the accumbens shell cannabinoid system as a modulating system is involved in aversive memory consolidation including passive avoidance memory.
\end{abstract}

Keywords. nucleus accumbens, passive avoidance task, memory consolidation, cannabinoid 
هييو كامٍ، آميكدال و كورتكس يرى فرونتال ارسال مىشود.

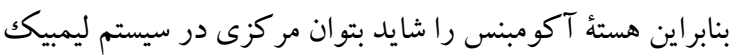
در نظر گرفت كه عمل آن يكيارجه سازى و تثبيت اطلاعات

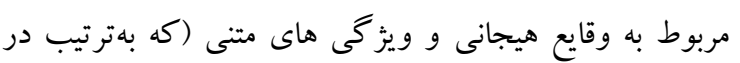

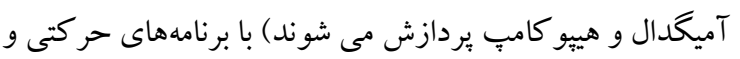

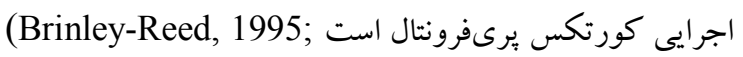
.Setlow,1999) سيستمهاى نوروترانسميترى و نورومدولاتورى متعددى در (Steckler, et al., 1998; Allan, تشكيل حافظه موثرندي (2007 كه ازبين آنها اندو كانابينوئيدها نقش تعيين كنندائ در

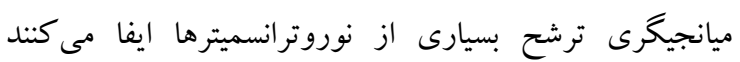
و در بسيارى از فرايندهاى (Lopez-Moreno et al., 2008)

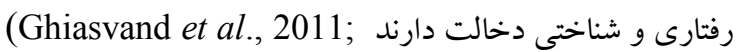
Esteban \& García-Sevilla, 2012) برخلاف نوروترانسميترهاى مرسوم، ترانسميترهاى بر گشتى به

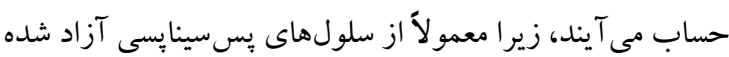

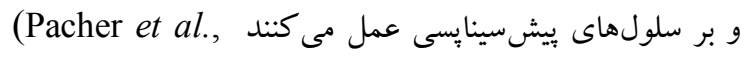

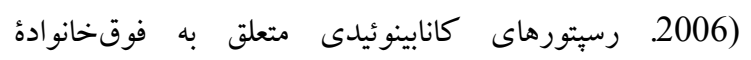

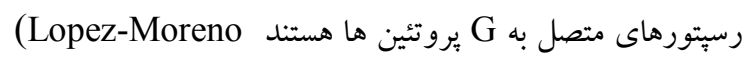
(CBR1) نوع يك رسيتورهاى كانابيوئيدى (Let al., 2008) ميانجى اصلى اثرات فيزيولوزى و روانشناختى كانابينوئيدها در

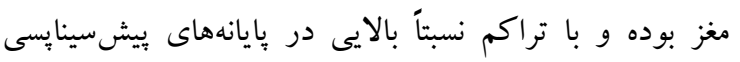

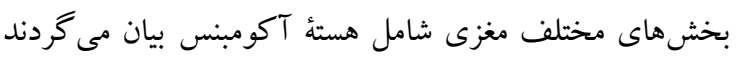
(Mackie, 2005; Wang, et al., 2010)

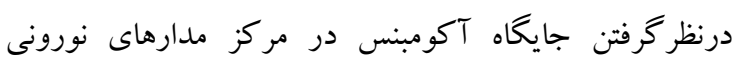

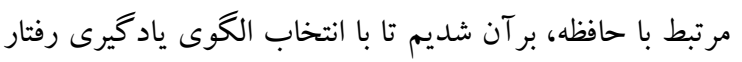

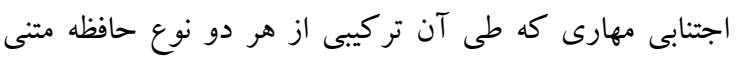

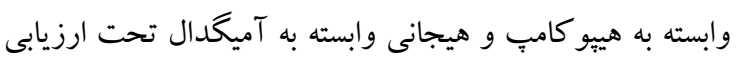

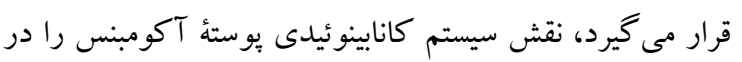

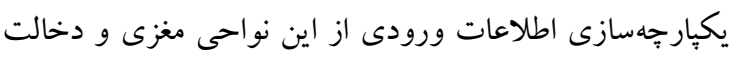
در تثييت هر دو نوع حافظه بررسى كنيم.
مقدمه

براساس نظرية تثبيت حافظه كه در سال ..19 توسط Muller و Pilzecker

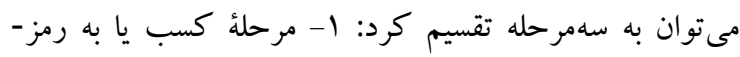

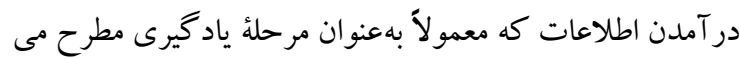

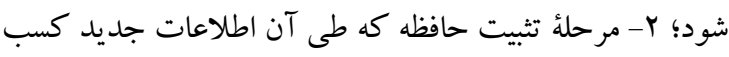

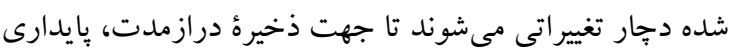

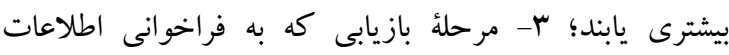

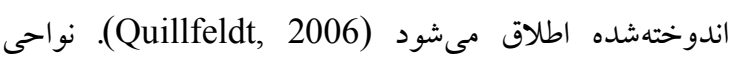
مغزى مهم مرتبط با تشكيل و تثبيت حافظه عبارتاند ازئ

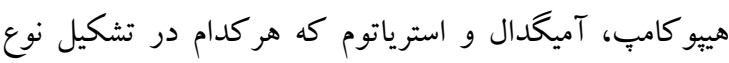

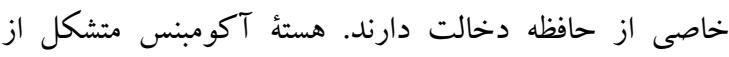

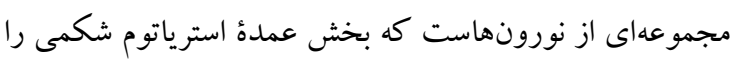

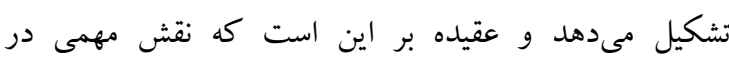

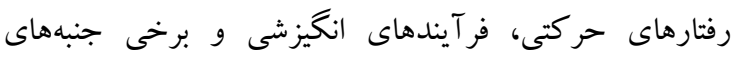

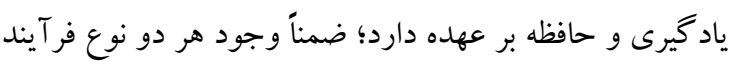

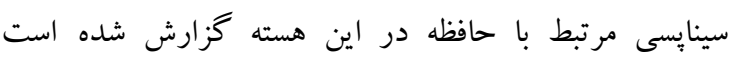
(Setlow, 1999; Lopez et al., 2008) جنبهاى مورفولوزى، عملكردى و آناتومى مى توان به دو بخش الخش

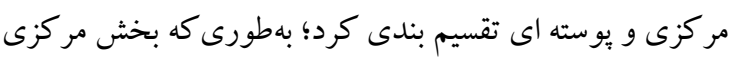

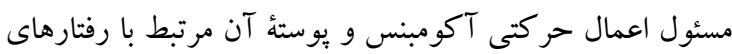

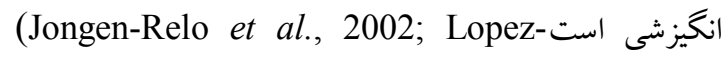
.Moreno et al., 2008) ورودى هايى متشكل از فيبرهاى كلو تاماترزيك، دويامينرزيك و

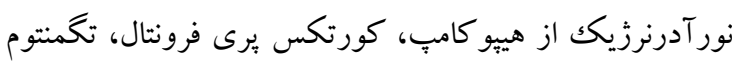

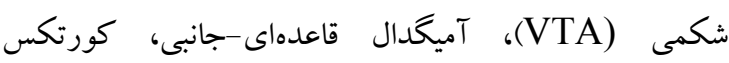
انتورينال و هسته هاى مختلف تالاموس به آكومبنس ارسال مى -

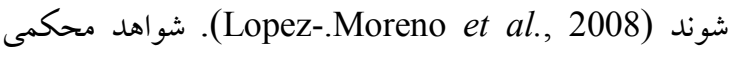

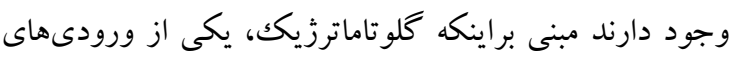

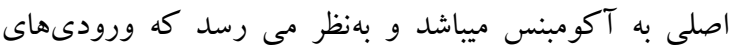

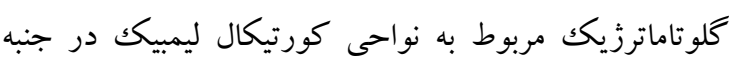
هاى شناختى و هيجانى رفتار مشاركت دارند. خروجى اين

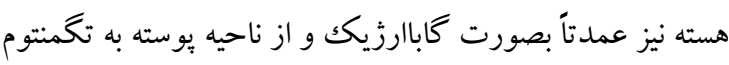

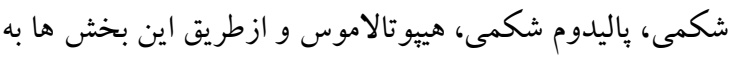


شناختى دارو با تغييرات احتمالى فعاليت حركتى حيوان، با

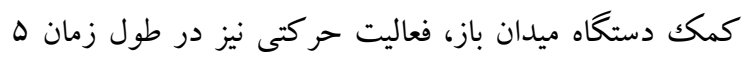

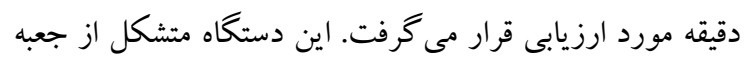

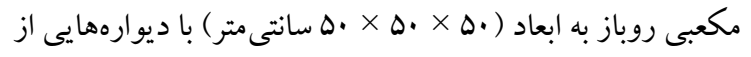

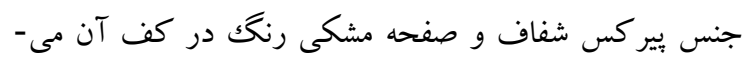

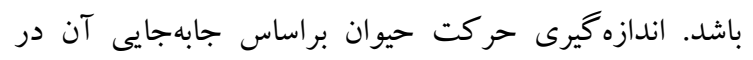

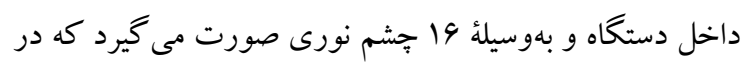
كنارههاى كف دستخاه تعبيه شدهاند.

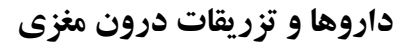

داروهاى ACPA (آكونيست قوى رسيتور CB1) و (آنتاكونيست رسيتور (CB1)

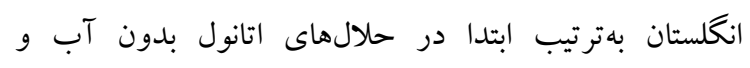
DMSO

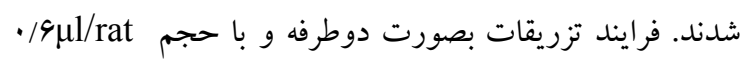

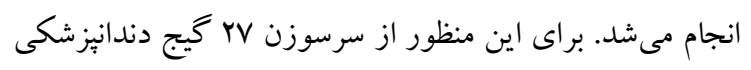

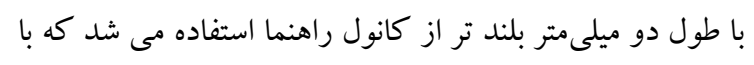
واسطه لوله باريك بِلى اتيلن به سرنگك هميلتون اتصال مى يافت.

\section{روشهاى آمارى}

ڤِ از بررسى دادهها بهوسيلة آزمون كلمو گراف-اسميرنوف،

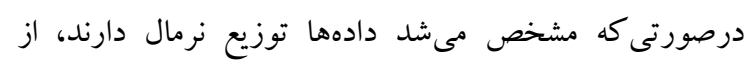

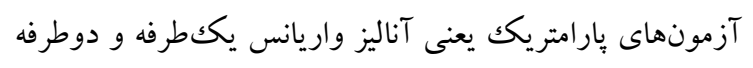
و همجنين از آزمون Post Hoc Tukey جهت مقايسة تفاوت هاى معنىدار گرووهاى آزمايشى استفاده مىشد. دادهها به-

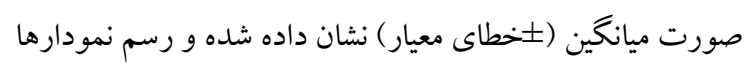

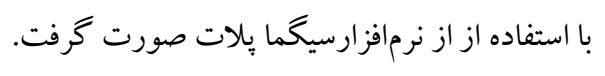

نتايج

ازآنجاكه بهدنبال عمل جراحى، در مواردى مشاهده مىشد كه

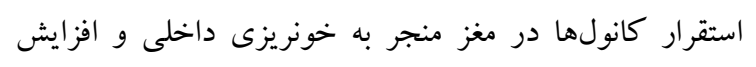

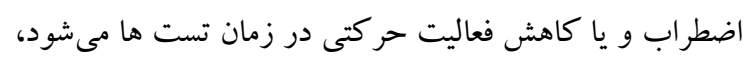

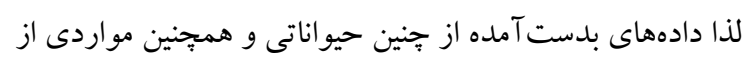

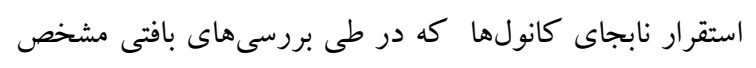
مى شد، از آناليزهاى آمارى حذف شدان لماند.

\section{مواد و روش ها \\ حيوانات و جراحى لـ}

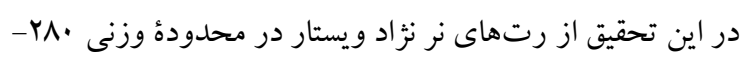
.

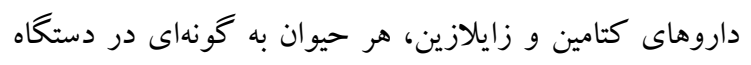

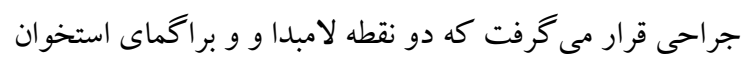

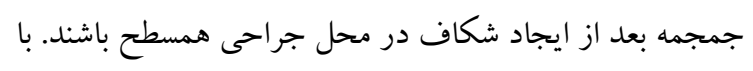

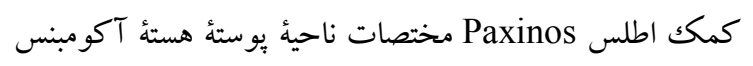
را بهدست آمده و يس از علامت كذارى و سوراخ كردن

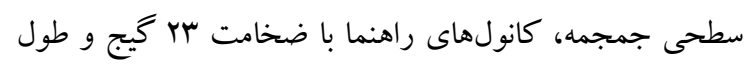

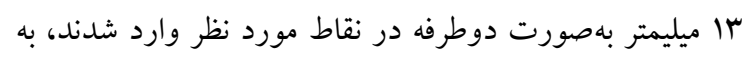

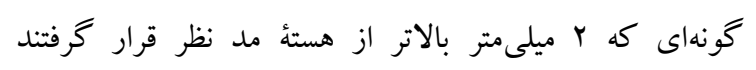
Paxinos \& Watson, 2007) براساس وزن بدن عبارت بودند از: مختصات جلويى-عقبى

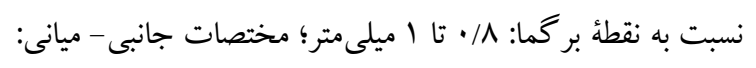

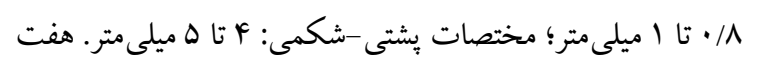

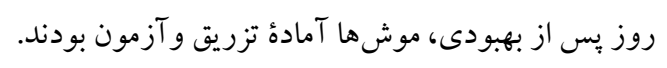

\section{مدل ياد ميرى اجتنابى غيرفعال}

الكوى يادگيرى اجتنابى مشتمل بر دو مرحلة آموزش و تست

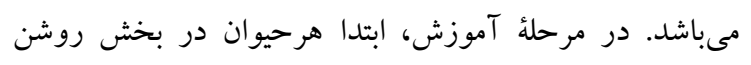

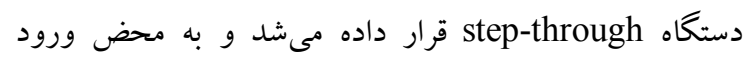

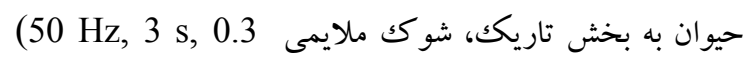

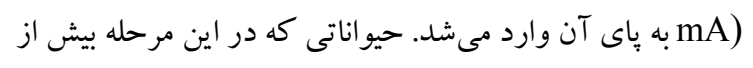

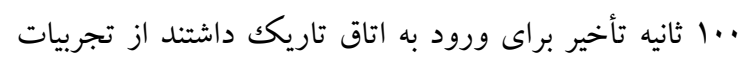

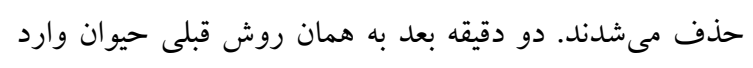

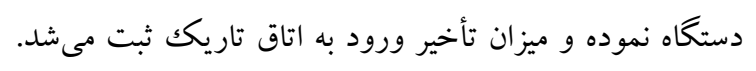

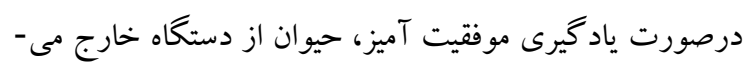

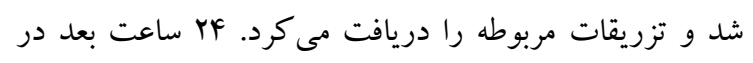

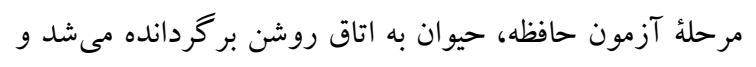

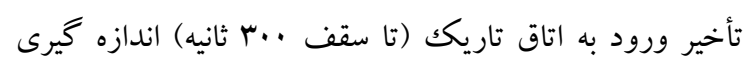

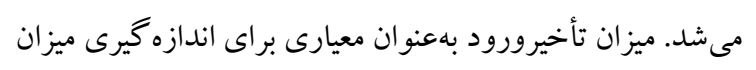
حافظه درنظر گرفته مىشد (Ghiasvand et al., 2011). بلافاصله پِس ازاين مرحله، براى اطمينان از عدم همبستخى اثر 
برمر حلة تثبيت حافظه اجتنابى در مقايسه با گروه كنترل (حامل ؟ا،

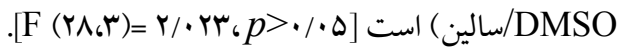

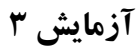

جهت بررسى وجود يا فقدان يكك تون كانابينوئيدى در ناحئ يوستهٔ آكومبنس، آزمايش سوم طراحى گرديد و و تأثير تزريق ACPA در حضور يا فقدان دوز بىاثر AM251 بر تثبيت حافظه اجتنابى مورد مقايسه قرار گرفت. تحليل واريانس دوطرفه نشان مىدهد كه تفاوت معنىدارى بين گروههاى دريافت كنده بهممراه (9.ng/rat) AM251

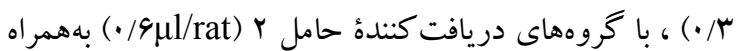
F] ازنظر تأثير بر حافظة اجتنابى مهارى وجود دارد تيمار

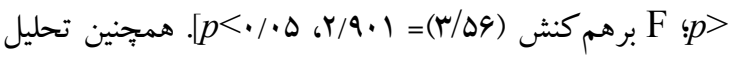

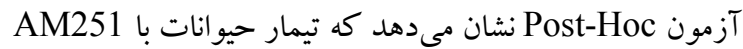
قبل از تزريق دوز موثر ng/rat) ACPA) به يوستهٔ آكومبنس

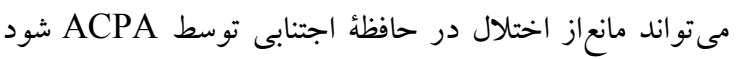

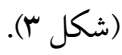

Step-through نتايج آزمون رفتارى در دستكاه آزمايش 1 آزمايش اول با هدف بررسى تأثير تزريق دوزهاى مختلف

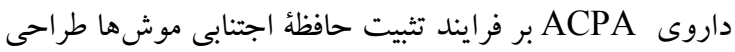

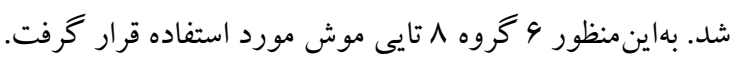

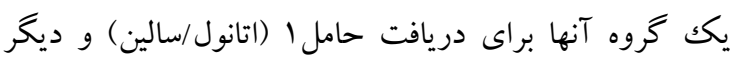
كروهها جهت دريافت ACPA در دوزهاى مختلف (

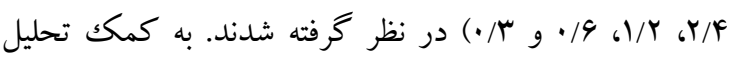
واريانس يككطرفه نشان داده شد كه تزريق ACPA به بو بوسته

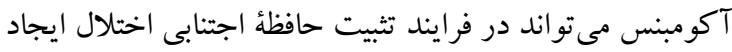

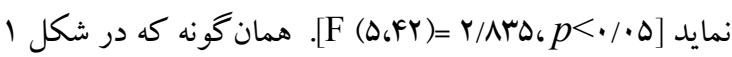

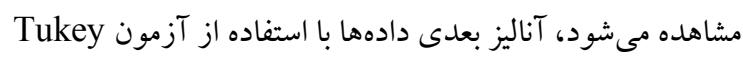

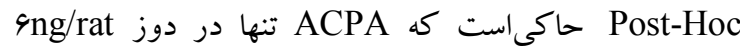
قادر به تأثير منفى در روند تثبيت حافظه است.

\section{آزمايش r}

شكل r نتايج حاصل از آزمايش دوم را نشان مى دهد. آناليز

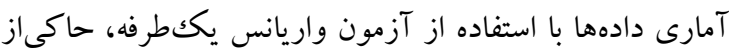

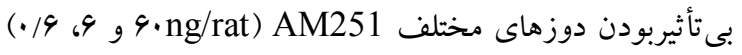

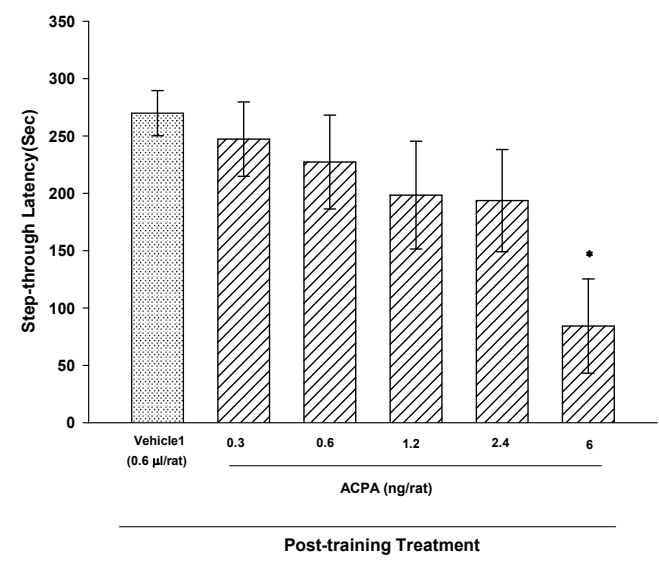

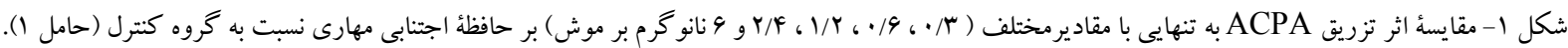

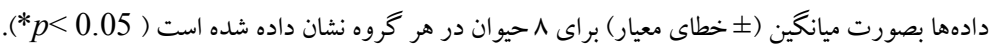

Fig. 1. The effects of ACPA administrations at different doses (0.3, 0.6, 1.2, 2.4 and $6 \mathrm{ng} / \mathrm{rat})$ on inhibitory avoidance memory consolidation compared with control group (vehicle1). Data have been represented in the form of mean $\pm \mathrm{SEM}$ of eight animals per group $\left({ }^{*} p<0.05\right)$. 


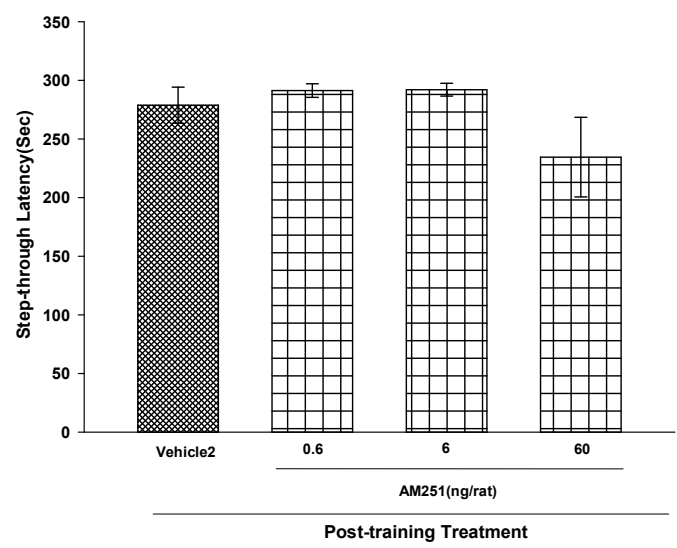

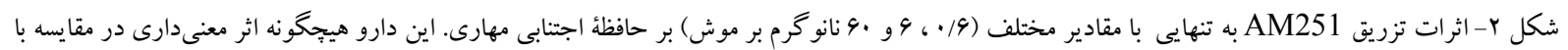
كروه كنترل (حامل r) نشان نداد.

Fig. 2. The effects of AM251administrations at different doses (0.6, 6and $60 \mathrm{ng} / \mathrm{rat})$ on inhibitory avoidance memory consolidation. The drug had no significant effect compared with the control group (vehicle 2).

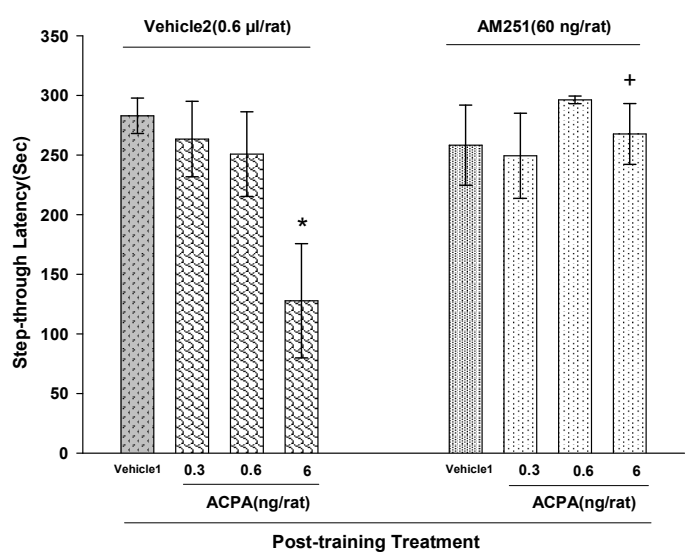

شكل r- اثر برهم كنش ACPA و AM251 بر تثيت حافظهُ مهارى اجتنابى. دو مجموعه جهار گروهى از حيوانات براى دريافت حامل ب يا AM251 ( .9 نانو گرم بر

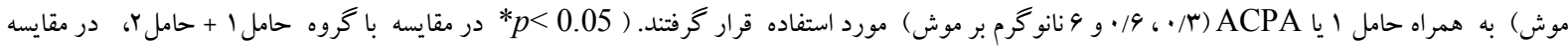

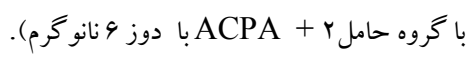

Fig. 3. The effects of interactions between AM251 and ACPA on inhibitory avoidance memory consolidation. The animals were divided into two sets of four groups and received vehicle2 or AM251 (60 ng/rat) plus either vehicle1 or ACPA $(0.3,0.6$ and $6 \mathrm{ng} / \mathrm{rat}) .{ }^{*} p<0.05$ compared with vehicle1-vehicle2 control group. ${ }^{*} p<0.05$ compared with vehicle2-ACPA (6 ng/rat).

فعاليت حركتى حيوانات در دستخاه ميدان باز (open-field)،

بين گروههاى تيمارى و كنترل آنها وجود ندارد (شكل هاى

$$
\text { الى (4) (9) }
$$

نتايج آزمون فعاليت حر كتى در دستغاه ميدان باز نتايج تحليل واريانس يككطرفه يا دوطرفه حاكى از آن است كه در هيج كدام از تجربيات فوق تفاوت معنىدارى ازنظرميزان 


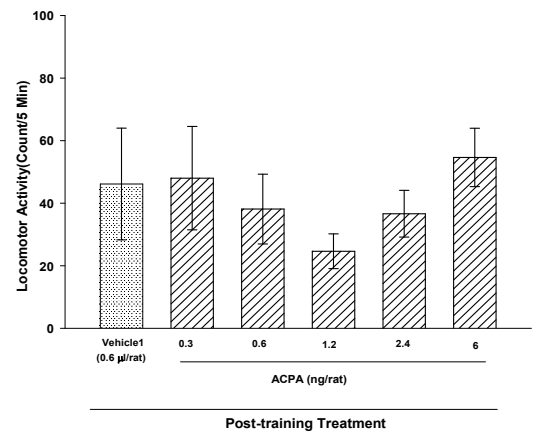

شكل F- مقايسٔ اثرتزريق دوزهاى مختلف ACPA بر فعاليت حركتى نسبت به گروه كنترل. دادهها بهصورت ميانگين (土 خطاى معيار) براى 1 حيوان در هر گروه

نشان داده شده است. [O

Fig. 4. The effects of post-training administrations of ACPA at different doses on locomotor activity compared with control group (vehicle1). Data have been represented in the form of mean \pm SEM of eight animals per group. [F (5, 42) $=0.718, p>0.05]$.

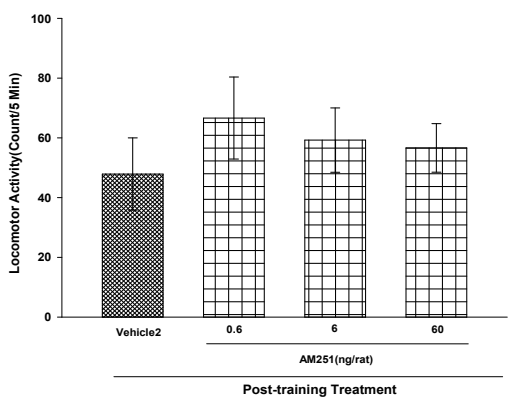

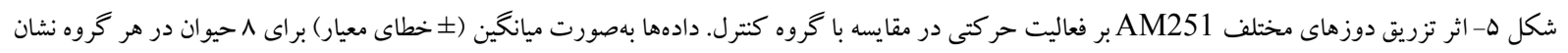

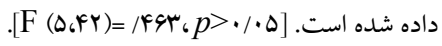

Fig. 5. The effects of AM251 administrations at different doses on locomotor activity in comparison with the control group. Data have been represented in the form of mean $\pm \operatorname{SEM}$ of eight animals per group. $[\mathrm{F}(5,42)=0.463, p>0.05]$.

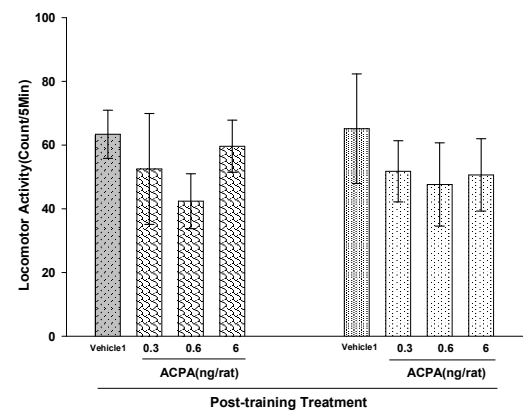

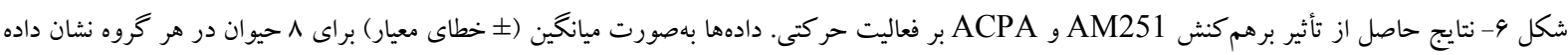

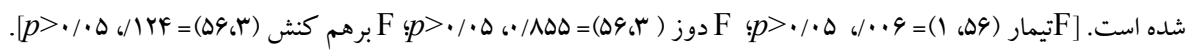

Fig. 6. The effect of the interaction between AM251 and ACPA on locomotor activity. Data have been represented in the form of mean $\pm \mathrm{SEM}$ of eight animals per group. $[\mathrm{F}$ treatment $(1,56)=0.006, p>0.05 ; \mathrm{F}$ dose $(3,56)=0.855, p>$ $0.05 ; \mathrm{F}$ interaction $(3,56)=0.124, p>0.05]$. 
سينايسى تحريكى و يا مهارى را بهصورت مستقيم يا غيرمستقيم، بر نورونهاى خروجى آكومبنس اعمال نمايند.

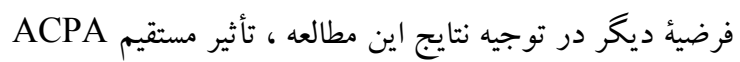

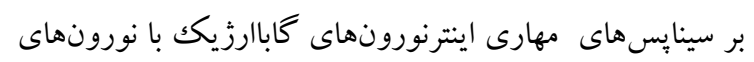

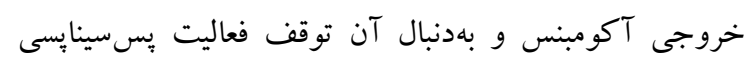

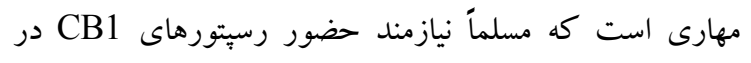

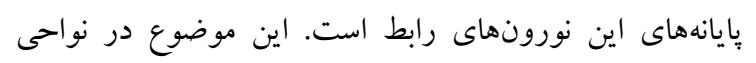

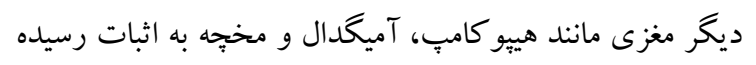

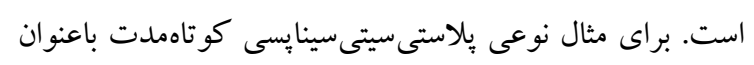

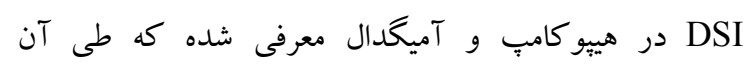
ديلاريزاسيون مختصرى از يكك نورون مى تواند انتقال سينايسى دئى

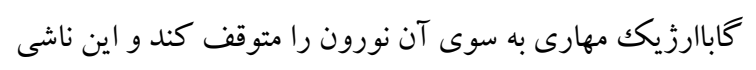

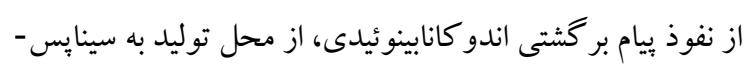
هاى مجاور (اينترنورونهاى كاباارزيكك) است كه منجر به مهار

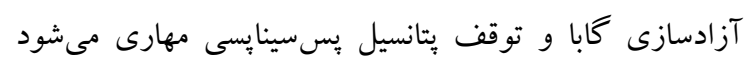

(Ohno-Shosaku et al., 2001) ازطرف ديخر نورونهاى مهارى خروجى آكومبنس، عمدتاً به

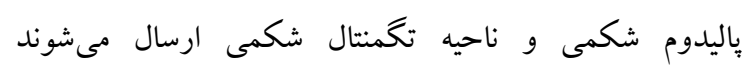
(Roozendaal et al., 2001)

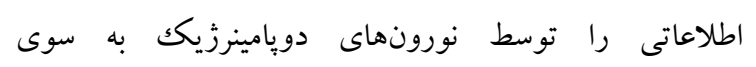

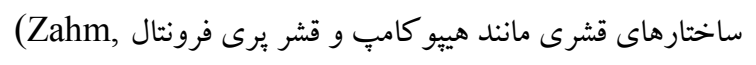
2000; Sesack \& Grace, 2010) خود نورونهاى خروجى آكومبنس گسيل مىدارند Pennartz) تع al., 1992)

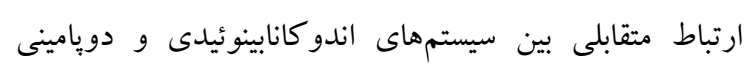

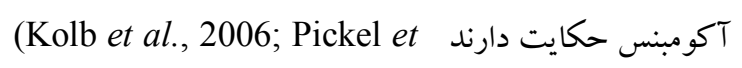
(al., 2006) بنابراين بر آيند اثر مستقيم و غيرمستقيم سيستم كانابينوئدى آكومبنس بر خروجىهاى كاباارزيكك اين ناحيه،

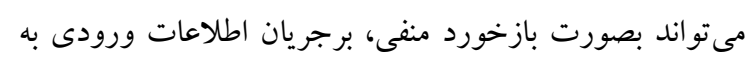

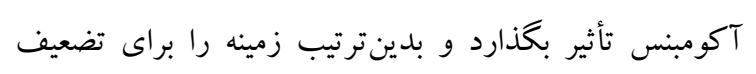

$$
\text { طولانى تر ذخيره اطلاعات فراهم سازد. }
$$

نتايج بهدست آمده از فعاليت حر كتى با استفاده از دستكاه ميدان

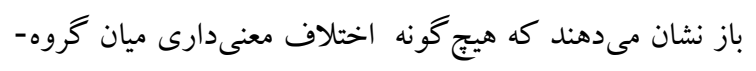

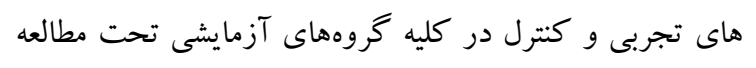

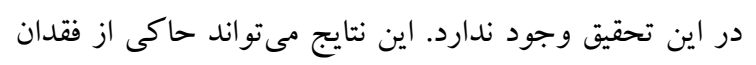

\section{بحث}

نتايج حاصل از اين مطالعه نشان داد كه تزريق ACPA به داخل يوسته آكومبنس به اختلال در تثبيت حافظة اجتنابى غيرفعال

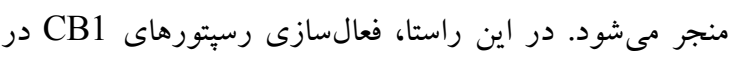

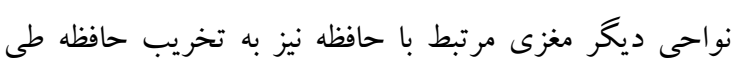

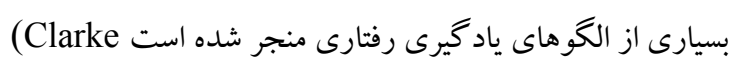
et al., 2008; Ghiasvand et al., 2011; Pedroza، بهعلاوه اينكه در خندين ناحية مغزى (Llinas et al., 2013) ازجمله هسته آكومبنس، فرايندهاى انتقال سينايسى و پِلاستى -

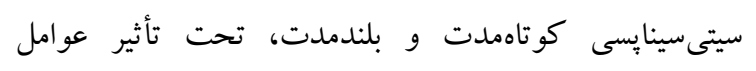
(Robbe et al., 2002; اندو كانابينوئيدى به اثبات رسيده استئست .Azad et al., 2004) نتايج بهدست آمده از تجربيات دوم و سوم حكايت از آن دارند

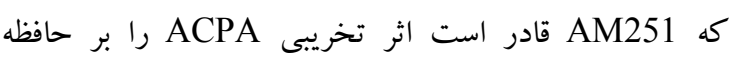
معكوس كند؛ ضمن اينكه تزريق آن بهتنهايى هيجگكونه تأثيرى

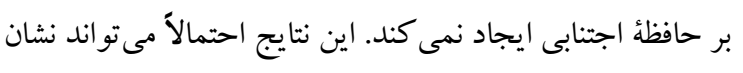

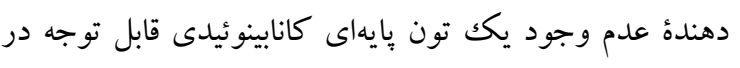

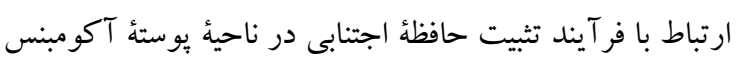

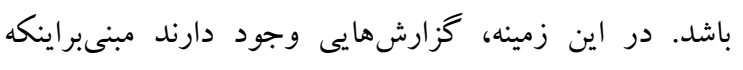

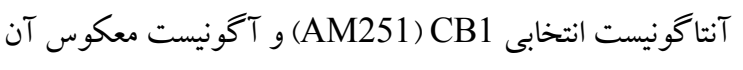

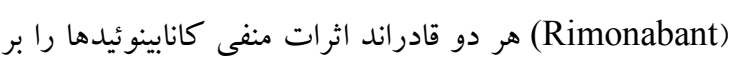

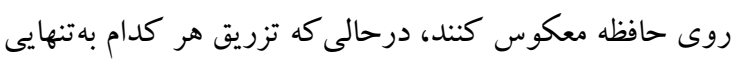

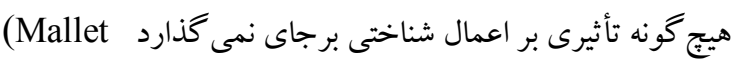
\& Beninger, 1998; Da \& Takahashi, 2002; .Alijanpour, 2013) آورانهاى تحريكى كلوتاماترزيك آكومبنس عمدتاً با نورون -

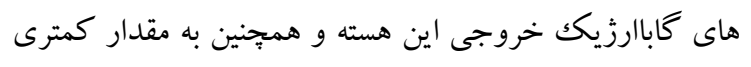

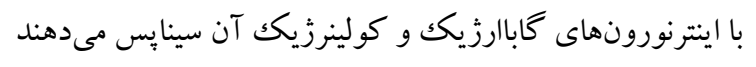
(Meredith et al., 1990; Shirayama \& Chaki, 2006) از طرف ديخر بررسىها نشان دادهاند كه رسيتورهاى \&B1

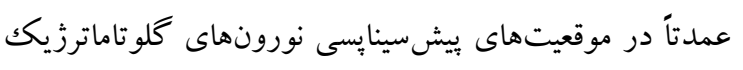
هسته آكومبنس قرار دارند (Hoffman \& Lupica, 2000).

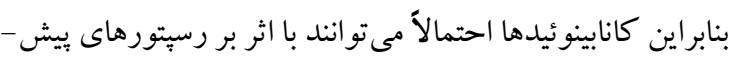

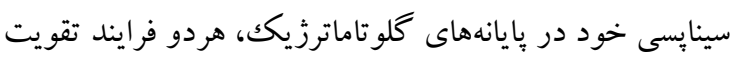




$$
\begin{aligned}
& \text { حاضر به اثبات مىرسد دخالت يوسته آكومبنس و بهويزه سيستم } \\
& \text { كانابينوئيدى آن در تعديل فرايند تثبيت حافظةٌ اجتنابى غيرفعال } \\
& \text { است كه قبلاً از طريق مراكز مغزى كدگذارى و يردازش شده الد }
\end{aligned}
$$

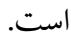

\section{References}

Alijanpour, S., Rezayof, A. and Zarrindast, M.R. 2013. Dorsal hippocampal cannabinoid CB1 receptors mediate the interactive effects of nicotine and ethanol on passive avoidance learning in mice. - Addiction Biology 18: 241-251.

Allan, V.K. 2007. Neurobiology of Memory and Anxiety: From Genes to Behavior. - Neural Plasticity 10: 71-83.

Azad, S.C., Monory, K., Mars Icano, G., Cravatt, B.F., Lutz, B., Zieglgansberger, W. and Rammes, G. 2004. Circuitry for associative plasticity in the amygdala involves endocannabinoid signaling. - Journal of Neuroscience 24: 9953-9961.

Brinley-Reed, M., Mascagni, F. and McDonald, A.J. 1995. Synaptology of prefrontal cortical projections to the basolateral amygdala: an electron microscopic study in the rat. - Neuroscience Letters 202: 45-48.

Clarke, J.R., Rossato, J.I., Monteiro, S., Bevilaqua, L.R., Izquierdo, I. and Cammarota, M. 2008. Posttraining activation of CB1 cannabinoid receptors in the CA1 region of the dorsal hippocampus impairs object recognition long-term memory. - Neurobiology Learning Memory 90: 374-381.

Da, S. and Takahashi, R. 2002. SR 141716A prevents delta 9-tetrahydrocannabinol-induced spatial learning deficit in a Morris-type water maze in mice. Progress in Neuro-Psychopharmacology \& Biological Psychiatry 26: 321-325.

Esteban, S. and García-Sevilla, J.A. 2012. Effects induced by cannabinoids on monoaminergic systems in the brain and their implications for psychiatric disorders. - Progress in Neuro-Psychopharmacology \& Biological Psychiatry 38: 78-87.

Ghiasvand, M., Rezayof, A., Zarrindast, M.R. and Ahmadi, S. 2011. Activation of cannabinoid CB1 receptors in the central amygdala impairs inhibitory avoidance memory consolidation via NMDA receptors. - Neurobiology of Learning and Memory 96: 333-338.

Hoffman, A.F. and Lupica, C.R. 2000. Mechanisms of cannabinoid inhibition of GABA (A) synaptic

$$
\begin{aligned}
& \text { تأثير فعاليت حر كتى حيوانات بر زمان تأخير آنها براى ورود به } \\
& \text { اتاق تاريكك باشد، به اين معنى كه زمانهاى تأخير منحصراً به } \\
& \text { وضعيتهاى حافظهاى حيوانات منتسب مىشوند و متأثر از تغيير } \\
& \text { در فعاليت حركتى آنها (بهدلايلى مانند اضطراب و كاهش } \\
& \text { توجه) درنظر كرفته نمىشوند. در مجموع، آنجه از نتايج مطالعه }
\end{aligned}
$$

transmission in the hippocampus. - Journal of Neuroscience 20: 2470-2479.

Jongen-Relo, A., Kaufmann, S. and Feldon, J. 2002. A differential involvement of the shell and core subterritories of the nucleus accumbens of rats in attentional processes. - Neuroscience 111: 95-109.

Kolb, B., Gorny, G., Limebeer, C.L. and Parker, L.A. 2006. Chronic treatment with Delta-9tetrahydrocannabinol alters the structure of neurons in the nucleus accumbens shell and medial prefrontal cortex of rats. - Synapse 60: 429-436.

López, J., Almaguer, W., Pérez, H., Frey, J.U. and Bergado, J.A. 2008. Opposite effects of shell or core stimulation of the nucleus accumbens on long-term potentiation in dentate gyrus of anesthetized rats. Neuroscience 151: 572-578.

López-Moreno, J.A., González-Cuevas, G., Moreno, G. and Navarro, M. 2008. The pharmacology of the endocannabinoidsystem: functional and structural interactions with other neurotransmitter systems and their repercussions in behavioral addiction. - Addiction Biology 13: 160-187.

Mackie, K. 2005. Distribution of cannabinoid receptors in the central and peripheral nervous system. Handbook of Experimental Pharmacology 168: 299325 .

Mallet, P.E. and Beninger, R.J. 1998. The cannabinoid CB1 receptor antagonist SR141716A attenuates the memory impairment produced by delta9tetrahydrocannabinol or anandamide. Psychopharmacology 140: 11-19.

Meredith, G.E., Wouterlood, F.G. and Pattiselanno, A. 1990. Hippocampal fibers make synaptic contacts with glutamate decarboxylase-immunoreactive neurons in the rat nucleus accumbens. - Brain Research 513: 329334.

Ohno-Shosaku, T., Maejima, T. and Kano, M. 2001. Endogenousannabinoids mediate retrograde signals from depolarized postsynapticneurons to presynaptic terminals. - Neuron 29: 729-738. 
Pacher, P., Batkai, S. and Kunos, G. 2006. The endocannabinoid system as an emerging target of pharmacotherapy. - Pharmacological Reviews 58: 389462.

Paxinos, G. and Watson, C. 2007. The Rat Brain in Stereotaxic Coordinates. - Academic Press, London. UK, $462 \mathrm{pp}$.

Pedroza-Llinas, R., Mendez-Diaz, M., RuizContreras, A.E. and Prospero-Garcia, O. 2013. $\mathrm{CB} 1$ receptor activation in the nucleus accumbens core impairs contextual fear learning. Behavioral Brain Research 237: 141-147.

Pennartz, C.M., Dolleman-Van Der Weel, M.J., Kitai, S.T. and Lopes da Silva, F.H. 1992. Presynaptic dopamine D1 receptors attenuate excitatory and inhibitory limbic inputs to the shell region of the rat nucleus accumbens studied in vitro. - Journal of Neurophysiology 67: 1325-1334.

Pickel, V.M., Chan, J., Kearn, C.S. and Mackie, K. 2006. Targeting dopamine D2 and cannabinoid-1 (CB1) receptors in rat nucleus accumbens. - Journal of Comparative Neurology 495: 299-313.

Quillfeldt, J.A. 2006. Behavioral Methods to Study Learning and Memory in Rats. - Universidade Federal do Rio Grande do Sul, Brazil, 383 pp.

Robbe, D., Kopf, M., Remaury, A., Bockaert, J. and Manzoni, O.J. 2002. Endogenous cannabinoids mediate long-term synaptic depression in the nucleus accumbens. $\quad-\quad$ Proceedings of the National Academy of Sciences of the United States of America 99: 8384-8388.
Roozendaal, B., De Quervain, D.J., Ferry, B., Setlow, B. and McGaugh, J.L. 2001. Basolateral amygdalanucleus accumbens interactions in mediating glucocorticoid enhancement of memory consolidation. - Journal of Neuroscience 21: 2518-2525.

Sesack, S.R. and Grace, A.A. 2010. Cortico-basal ganglia reward network: microcircuitry. Neuropsychopharmacology 35: 27-47.

Setlow, B. 1999. The Nucleus accumbens and learning and memory. - Journal of Neuroscience Research 49: 515-521.

Shirayama, Y. and Chaki, S. 2006. Neurochemistry of the nucleus accumbens and its relevance to depression and antidepressant action in rodents. - Current Neuropharmacology 4: 277-291.

Steckler, T., Sahgal, A., Aggleton, J.p., Drinkenburg, W.H. and Planck, M. 1998. Recognition memory in rats--III. Neurochemical substrates. - Progress in Neurobiology 54: 333-348.

Wang, W., Sun, D., Pan, B., Roberts, C.J., Sun, X., Hillard, C.J. and Liu, Q. 2010. Deficiency in endocannabinoid signaling in the nucleus accumbens induced by chronic unpredictable stress. Neuropsychopharmacology 35: 2249-2261.

Zahm, D.S. 2000. An integrative neuroanatomical perspective on some subcortical substrates of adaptive responding with emphasis on the nucleus accumbens. Neuroscience and Biobehavioral Reviews 24: 85-105.

Rasekhi, K., Oryan, S., Nasehi, M. and Zarrindast, M.R. 2015. The role of cannabinoid system in consolidation of passive avoidance memory in the shell of nucleus accumbens in male Wistar rats. - Nova Biologica Reperta 2: 113-121.

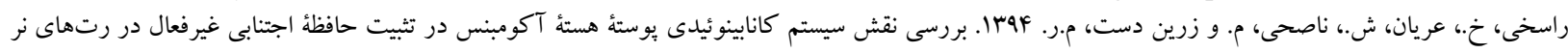

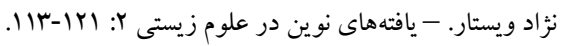


